\title{
CLARICE LISPECTOR: UM DIÁLOGO ENTRE FILOSOFIA E LITERATURA*
}

\author{
Maria Elisa de OLIVEIRA**
}

RESUMO: O presente trabalho visa apresentar algumas considerações em torno do confronto/encontro entre filosofia e literatura. A produção ficcional de Clarice Lispector, no ámbito da literatura brasileira contemporánea, nos fornece a oportunidade de analisarmos a obra de arte a partir de um enfoque interdisciplinar.

UNITERMOS: Filosofia; literatura; filosofia e literatura; enfoque interdisciplinar; Clarice Lispector; literatura brasileira;

A estreita vinculação entre filosofia e literatura nem sempre existiu e uma reaproximação entre ambas data de uma época aliás bastante recente. Sem discutirmos em profundidade os vários indícios que teriam contribuído para esse novo reencontro, não poderíamos, contudo, deixar de mencionar a importância de alguns deles.

O agravamento da crise da metafísica, principalmente a partir dos questionamentos de Nietzsche, pode ser apontado como um fator relevante. Foi ele quem teria sentido de forma aguda "o grande embaraçó' 'de saber, por exemplo, se a filosofia não seria, ela mesma, literatura (17, p. 69). Com isso, o privilégio do discurso filosófico que havia pelo menos sonhado em se colocar sempre como um dizer puro (Nota A) começa a sofrer, a partir de então, um certo abalo.

O surgimento ainda de um certo tipo de filosofia que assumirá como tarefa, como dizia Merleau-Ponty, não mais explicar o mundo a partir de certos pressupostos metafísicos, inteiramente abstratos, e sim "formular uma experiência do mundo" um contato com o mundo que precede todo "pensamento sobre o mundo" contribuiu para que "a tarefa da literatura e da filosofia já não possam andar separadas" (16, p. 55). Estamos nos' referindo à filosofia fenomenológica ou existencial cuja sistematização somente se deu nas décadas que permearam as duas grandes guerras. A partir daí, a união dos esforços em torno, por exemplo, do tema da existência, não implica, evidentemente, a fusão dos métodos e objeto que caracterizam a filosofia e a literatura. Enquanto a primeira busca no ser e no homem o elemento de universalidade, válido, em princípio, para a totalidade das contingências do existir, na segunda, como afirma José Fernandes, "a personagem é um ser de linguagem, símbolo e pensamento do ser real" (3, p. 25), engajado em situações existenciais particulares, bem definidas.

No âmbito da literatura brasileira contemporânea podemos sentir a estreita ligação entre filosofia e literatura no aparecimento da obra ficcional de Clarice Lispector, razão pela qual esco-

\footnotetext{
* Este texto foi elaborado por ocasião da preparação da dissertação de mestrado (em andamento) na área de filosofia, a ser apresentada na PUC/SP.

** Departamento de Filosofia - Faculdade de Educação, Filosofia, Ciências Sociais e da Documentação UNESP - 17500 - Marília - São Paulo - SP.
} 
Ihemos este tema como objeto de nosso artigo. A produção ficcional clariceana alinha-se ao lado de outras, com a de Guimarães Rosa, apenas para citar um exemplo, que como ela apresenta em suas obras elementos que permitem tal aproximação. Tanto um como outro revelam um nexo entre criação literária e reflexão filosófica, mostrando assim que pode haver compatibilidade - bastante equilibrada no caso de Clarice - entre estas duas direções do espírito. Mas, diferentemente de Guimarães Rosa cuja obra evoca conteúdo de ordem mais mítica (6) a ficção de Clarice revela uma temática marcadamente existencial. Nela, o entrelaçamento entre as franjas da criação artística e a especulação filosófica se tece, produzindo certos "motivos especificos" que guardam grande afinidade com alguns temas (a náusea e a angústia; o nada, o fracasso etc.) desenvolvidos pelas filosofias da existência, especialmente a de tipo sartreano (Nota C).

Certos críticos fazem severos reparos a isto que comumente se denominou existencialismo de Clarice, considerando sua obra como excessivamente reduzida à esfera do puramente intelectual, onde existiria uma sobrecarga de digressões e tiradas "filosofantes". Segundo eles (Nota D), tais elementos devido ao seu excesso, em lugar de enriquecer a linguagem literária acabam por produzir um sério prejuízo à trama romanesca. Contudo, se as indagações filosóficas estão presentes na obra de Clarice, elas aparecem sempre sujeitas aos embates e à dinâmica que caracterizam o campo específico literário, como a paródia (Nota B), a ironia, a refutação no diálogo, só para citar alguns exemplos.

Assim sendo, a especulação filosófica em Clarice Lispector não se introduz como um corpo estranho em sua obra e nem tampouco rompe a unidade e o fluxo da linguagem romanesca. $A$ maioria dos críticos, aliás, reconhece que Clarice soube trazer um enriquecimento filosófico à linguagem literária, operando a passagem de um campo para o outro sem o recurso da imediatez pura e simples, mas utilizando, devidamente, as necessárias mediações que se interpõem entre uma linguagem de caráter mais filosófico e a trama ficcional. Sabemos que em todas as operações nas quais se desprezam as mediações, violentando-se a especificidade do discurso, quem perde é o romance. Este deixa de ser quando abdicamos ao que the é especiffico, ainda que tentemos enriquecê-lo através de uma operação que, no entanto, não lhe cabe.

Afirmar, porém, que a ficção clariceana está estreitamente vinculada e aparentada à filosofia não nos leva a concluir que o critério de avaliação de sua obra literária esteja nas suas intenções conscientemente filosóficas. Ao contrário, Clarice nunca esteve preocupada em fazer de sua arte um instrumento deliberado com a intenção de se veicular as duas coisas literatura e filosofia, como fez Sartre, por exemplo.

Poderiamos mesmo assegurar que o impulso artístico em Clarice talvez se explique muito mais pela necessidade vital de se compreender a si mesma e ao mundo que a cerca, do que pela preocupação propriamente intelectual de defender esse ou aquele sistema, essa ou aquela idéia filosófica. Com isto, o risco de sobrepor o filosófico ao artístico se torna menor, muito embora a consciência dos próprios valores por parte do escritor não constitua, por si mesma, a causa da diminuição da força emotiva da arte literária. Como prova, poderíamos mencionar, por exemplo, a obra de Camus num reconhecimento de tal possibilidade.

Lembrariamos ainda que a própria Clarice nos fornece, principalmente nas poucas entrevistas que concedeu e em suas crônicas (Nota E), alguns comentários que demonstram até uma certa aversão em assumir como profissão a "carreira" de escritor. São suas palavras:

"Outra coisa que não parece ser entendida pelos outros é quando me chamam de intelectual e eu digo que não sou. (...) Ser intelectual é usar sobretudo a inteligência, o que eu não faço: uso é a intuição, o instinto. (...) Literata também não sou porque não 
tornei @ fato de escrever livros 'uma profissão', nem uma 'carreira'. Escrevi-os só quando espontaneamente me vieram, e só quando eu realmente quis” (11, p. 216).

Acrescente-se aí a dificuldade de sabermos, com exatidão, se a escritora brasileira recebeu ou não influências de outros autores e mesmo pensadores. Se nos basearmos nas suas próprias declarações, em algumas entrevistas, e se acolhermos os depoimentos daqueles que conviveram longamente com ela $(1, p .67 ; 4, p .2)$, ficamos seguramente cientes de que essas influências não existiram ou, pelo menos, não desempenharam um fator decisivo na composição de sua obra. Permanecem, então, a forte marca de sua originalidade e a sua singular experiência humana.

Clarice consegue poīs colocar,através da linguagem literária, questões que têm um alcance ontológico para a existência humana (Nota F). Mesmo não empregando, deliberadamente, nenhuma palavra do vocabulário filosófico, poderíamos mesmo afirmar que delas decorreriam os chamados "filosofemas" e não o contrário,que significaria extrair do discurso filosófico elementos para a composição de um romance (Nota G).

Esta parece ser, na verdade, uma habilidade sempre presente nos grandes romancistas, qualidade tão bem ressaltada por Merleau-Ponty quando afirma que a "obra de um grande romancista está carregada de duas ou três idéias filosóficas", embora não caiba a este tematizá-las e sim "fazê-las existir diante de nós como coisas" (16, p. 45).

Definida pela crítica em geral como uma produção literária altamente metafísica, a obra de Clarice procura muito mais interrogar o mundo e nele a própria condição humana, do que simplesmente narrar e contar histórias apenas imagináveis. Sob este prisma a autora pode ser definida como uma ficcionista-filósofa já que, ao longo de seu percurso criativo, buscou incansavelmente compreender-se e explicar-se na existência.

Deixando de lado o fato de que essa constante preocupação da autora brasileira com o sentido possivel/impossivel da existência possa, finalmente, mergulhar os seus personagens na angústia ou no tédio, observamos, entretanto, que tal interesse vem acompanhado, igualmente, pelo interesse em relação ao próprio ofício de escrever. Viver e escrever poderiam ser tomados como reflexos de uma mesma atividade/arte. Ambos, portanto, (o narrar e o existir) assumem em Clarice Lispector o mesmo destaque e importância, muito embora isto não exclua o "dualismo interior em que debateu-se a romancista: o desejo de viver ou analisar a consistência da vida; participar do sangue grosso da existência ou atirar-se no jogo da escritura" (21, p. 111). São suas palavras:

"Minhas intuições se tornam mais claras ao esforço de transpô-las em palavras. É neste sentido, pois, que escrever me é uma necessidade" (13, p. 22).

Em outra parte ela declara:

“(...) o que atrapalha ao escrever é ter de usar palavras. É incômodo. Se eu pudesse escrever por intermédio de desenhar na madeira ou de alisar uma cabeça de menino ou passear pelo campo, jamais teria entrado pelo caminho da palavra" (13, p. 100).

De fato, todo esforço de Clarice se empenha num corpo a corpo com a linguagem, tentando assim extrair das palavras - num trabalho semelhante à garimpagem, aqueles elementos que permitiriam traduzir a quidditas, o verdadeiro ser das coisas. No entanto, vivenciando, ao mesmo tempo, a oposição entre ser e dizer, a autora é levada a fazer, por vezes, um recuo e uma "escavação" radicais. Conseqüentemente, o tema do silêncio, como fonte e fim da linguagem, vem ocupar um lugar importante e está constantemente presente na obra de Clarice (Nota H). 
A leitura da obra ficcional de Clarice nos leva assim a incluí-la entre aqueles escritores e artistas recentes que se mostram obcecados pela missão impossivel de dar nome ao inominável, de "reproduzir o irreproduzivel", ou, enfim, de "dizer o indizivel". Na mesma crônica citada, por nós, na página anterior, Clarice acrescenta:

"Sou uma amadora?

O que sou então? Sou uma pessoa (...) que pretendeu pôr em palavras um mundo ininteligível e um mundo impalpável" (11, p. 217)

Em outra parte ela insiste:

"Escrever é procurar entender, é procurar reproduzir o irreproduzivel, (grifo nosso) é sentir até o último fim o sentimento que permaneceria apenas vago e sufocador" (11, p. 191).

Acreditamos, com isso, que a produção ficcional de Clarice poderia, facilmente, interessar à crítica desconstrutora (Nota I), já que ambas insistem em algo que sempre escapa à linguagem, ou seja, à lembrança do não-dito assim como do indizível. Que outra coisa podemos entender quando nos deparamos com as seguintes passagens de $A$ paixão de Clarice?

"A linguagem é o meu esforço humano. Por destino tenho que buscar e por destino volto com as mãos vazias. Mas volto com o indizível. O indizivel só me poderá ser dado através do fracasso de minha linguagem. Só quando falha a construção, é que obtenho o que ela não conseguiu" (12, p. 211)

Não poderiamos diagnosticar aí os sintomas de uma crise intensamente vivida em nosso tempo e que se estende até a própria palavra? Estamos nos referindo à "morte de Deus" e com ela à perda do centro como reconhece Derrida, centro que durante séculos lastreou o pensamento, orientou o julgamento e organizou a experiência. A extensão dessa perda de direção que impede a apreensão, por exemplo, de um significado unívoco para os textos literários e filosóficos, se reflete numa crise radical da palavra, tão bem analisada por Foucault (5).

Dentre os críticos que formularam uma opinião explícita sobre o caráter decididamente metafísico da produção ficcional de Clarice Lispector citariamos Alfredo Bosi. Num estudo realizado sobre A paixão segundo $G$. $H$. (1964) o crítico nota que esse romance, negando-se a permanecer no nível apenas psicológico, foi capaz de dar o "salto" para o nível metafísico (2, $\mathrm{p}$. 476). A fim de ilustrar esse "salto", Alfredo Bosi destaca um trecho que poderia servir como exemplo consciente e deliberado, pelo menos da intenção da narradora na abordagem de uma realidade maior:

"Além do mais a 'psicologia' nunca me interessou. O olhar psicológico me impacientava e me impacienta, é um instrumento que só transpassa. Acho que desde a adolescência eu havia saído do estágio psicológico" (12, p. 24).

Esta dimensão metafísica na obra clariceana foi apontada pela crítica literária como algo novo entre nós e, neste sentido, ela assume um caráter inaugural, dando início ao chamado "romance metafísico" ou à "ficção metafísica" na moderna literatura brasileira. Chamando novamente a atenção para o fato de Clarice não ser propriamente uma filósofa e sim uma escritora, lembraríamos, a propósito, as palavras de Olga de Sá.

"Ao dizer que ela inaugura entre nós o romance metafísico quisemos significar: Clarice não é um filósofo, um pensador, mas uma escritora, fundamentalmente comprometida com o ser sob linguagem; ou melhor, com a linguagem espessura do ser" (21, p. 19) 
Na visão, principalmente, das filosofias da existência, o existir pressupõe o estar-lançado no tempo e como tal o ser do homem está essencialmente ligado ao processo de temporalização. Sem nos aprofundarmos aqui na análise desse processo (10) poderíamos desde já eleger a noção de temporalidade (Nota J) como um campo fecundo por onde, como lembra Benedito Nunes, em nossa época, se encontrariam filosofia e literatura (20, p. 204). Isto porque "é justamente o tempo aquele horizonte de confluência da realidade problemática (...) com a função, também problemática, do ato de narrar, diretamente visada pelo narrador e intrínseca ao desenvolvimento do romance" (20, p. 202).

A análise da categoria temporal na produção ficcional clariceana adquire importância tão fundamental que muitos críticos chegaram a ver em Clarice "a ficcionista do tempo, por excelência" (15, p. 192). É claro que o uso dessa categoria na obra da romancista brasileira exigiria um longo e minucioso exame que não podemos fazer aqui. Apesar disso, podemos ensaiar algumas observações mais gerais.

É assim que podemos formular a questão: como entender o viver/existir e o escrever/narrar?

Ora, quer participemos "do sangue grosso da existência", quer nos lancemos "no jogo da escritura", ambos podem ser compreendidos sob o mesmo fundamento: o tempo. E mais: se o "viver é perigoso", como várias vezes declara o personagem Riobaldo, de Guimarães Rosa, o narrar também o é e Clarice tem plena consciência disso. Em algumas passagens lemos:

"Como em tudo, no escrever também tenho uma espécie de receio de ir longe demais: Que será isso? Por quê? Retenho-me, como se retivesse as rédeas de um cavalo que poderia galopar e me levar Deus sabe onde" (13, p. 64).

Os personagens dos romances de Clarice estão, em sua maioria, interessados basicamente em construir uma identidade mais autêntica. Sem discutirmos porém esta noção ou se eles realmente obtêm êxito ou não nessa tentativa, os críticos observam que nesta reconstrução a fabulação clariceana, freqüentemente, se rarefaz. No caso de Joana, personagem do primeiro romance de Clarice, isto acontece "em benefício da densidade metafísica da pesquisa do tempo" (21, p. 81). Assim, a respeito de Perto do coração selvagem (1944), Olga de Sá complementa: "os fatos são insignificantes no mais exato sentido etimológico" (21, p. 81).

Contudo, se tomarmos $A$ paixão não podemos deixar de admitir que algo mudou. Aqui, podemos acompanhar o árduo e penoso/carente esforço da personagem-narradora G. H. que procura retraçar os acontecimentos, organizando-os e reunindo-os, a fim de lhes imprimir uma forma. Neste anseio de dar um formato à vida e às coisas na tentativa de compreendê-las, a personagem-narradora - uma escultora amadora, como ela mesma confessa - não despreza as mínimas coisas: pára longos momentos à mesa, após o café, construindo formas com o que sobrou do miolo de pão.

"Quanto à minha chamada vida íntima, talvez também tenha sido a escultura esporádica o que lhe deu um leve tom de pré-climax - talvez por causa do uso de um certo tipo de atenção a que mesmo a arte diletante obriga. Ou por ter passado pela experiência de desgastar pacientemente a matéria até gradativamente encontrar sua escultura imanente; ou por ter tido através ainda da escultura, a objetividade forçada de lidar com aquilo que já não era eu" (12, p. 25).

Todo o penoso e árduo esforço da personagem-narradora G. H. em busca não só da compreensão daquilo que the ocorreu como um fato insólito - cujo clímax se dá por ocasião da manducação da barata - mas também em busca da compreensão de si mesma, se constrói no 
texto, através de um movimento que se revela ora impotente, ora vitorioso. Eis como o romance se inicia:

“_ _ _ _ _ estou procurando, estou procurando. Estou tentanto entender. Tentando dar a alguém o que vivi e não sei a quem, mas não quero ficar com o que vivi” (12, p. 5).

Mais adiante lemos:

"Será preciso coragem para fazer o que vou fazer: dizer. E me arriscar à enorme surpresa que sentirei com a pobreza da coisa dita. Mal a direi e terei que acrescentar. não é isso, não é isso!" (12, p. 16).

O leitor terá assim a oportunidade, especialmente neste romance de Clarice Lispector, de acompanhar de perto a penúria/força do narrar.

Contudo, se o "viver não é relatável", se "viver não é vivível" como expressa a personagem G. H., numa outra forma ao "viver é perigoso" de Riobaldo, tanto o existir/viver quanto o narrar/relatar dependem do tempo como movimento da existência finita em seu cuidado e inquietude. Ao mesmo tempo, se falta à personagem-narradora o discernimento do princípio e do fim - tanto assim que o romance começa e termina com seis travessões, sugerindo talvez um "recorte" ou mesmo que algo pode vir antes e continuar ao "término" de seu relato - é porque, como observa Benedito Nunes, o tempo que nos ultrapassa pode também nos limitar (20, $p$. 203).

No caso ainda do romance que vimos comentando, as unidades temporais que se interligam no processo da narração, produzindo o tempo, enquanto a narrativa vai sendo tecida, apresentam a tentativa - sempre ensaiada pela autora - de aproximar o viver e o narrar. Aqui, a distância entre o presente (o "hoje") e o passado (o "ontem") é bastante reduzida o intervalo entre o ocorrido e o relato é apenas de vinte e quatro horas (Nota K).

Por outro lado, enquanto a narrativa vai sendo construída, podemos seguir a trajetória (itinerário) da personagem-narradora que, aos poucos, atinge um conhecimento pleno de si mesma e do mundo. Tudo isso é realizado em meio a uma intensa reflexão por parte da própria narradora, conferindo ao romance um caráter de ensaio filosófico.

\section{NOTAS}

A - Por dizer puro entendemos uma palavra, um discurso puramente transparente àquilo que eles deveriam imediatamente significar: a verdade, o ser, o absoluto etc.

B - No caso da obra de Clarice Lispector recomendamos a leitura de (22), trabalho apresentado para a obtenção do grau de doutor. Neste trabalho a autora analisa o tema da paródia em alguns romances de Clarice, descartando, logo de início, a acepção corrente de burla e sátira, para a focalizar o sentido de "paródia séria".

C - Na opinião do crítico paraense Benedito Nunes a concepção-do-mundo de Clarice Lispector, inerente à sua obra, vista no seu conjunto, revela, no entanto, um afastamento em relação ao existencialismo sartreano. Isto se dá, principalmente, no romance $A$ paixão segundo $G$. $H$. devido à presença de uma "perspectiva mística" ver, a este respeito: (18) e (19), ambos do mesmo autor.

D - Ver, a este respeito, a análise que o.crítico Luiz Costa Lima (10, p. 449-72) faz da produção ficcional de Clarice Lispector até 1961. Neste estudo o autor chega a enumerar o que ele considera os "defeitos fundamentais" que prejudicam a matéria romanesca da escritora brasileira. 
E - Clarice Lispector colaborou vários anos para o Jornal do Brasil, como cronista. Seus filhos, Paulo e Pedro Gurgel Valente, reuniram em livro, em ordem cronológica, todas as suas contribuiçōes, aos sábados, de agosto de 1967 a dezembro de 1973. Ver, a este respeito: (11).

F - Benedito Nunes formulou de uma maneira completa, a recomposição de um quadro temático-filosófico da escritora brasileira, inserindo a sua produção ficcional - principalmente na escala do romance - no contexto das filosofias da existência (ver Nota C).

G - Este parece ser o caso, por exemplo, do romance $A$ insustentável leveza do Ser, de Milan Kundera (cf. 14, p. 10).

$\mathrm{H}$ - Benedito Nunes examina essa questão, principalmente, nos romances $A$ maçã no escuro e $A$ paixão segundo G. H. de Clarice Lispector (cf. do mesmo autor: 19, p. 129-39).

1 - A tarefa desconstrutora de J. Derrida envolve uma releitura crítica da filosofia ocidental representada por alguns filósofos (Platão, Rousseau, Hégel, Heidegger e outros) com o objetivo de pensar o que a filosofia deixou impensado e de escrever aquilo que excede cada livro. Das suas expressōes a mais sugestiva para evocar aquilo que excede a linguagem é o neologismo, criado por ele, "différance" (consultar: 8, p. 22).

J - Para uma visão mais completa dessa noção, que se distingue da noção de tempo, consultar: (7, p. 79-96).

K - Para uma visão mais ampla e detalhada da categoria do tempo na ficção de Clarice Lispector, consultar: (21, p. 73-101).

OLIVEIRA, M. E. - Clarice Lispector: un dialogue entre philosophie et littérature. Trans/Form/Ação, São Paulo, 11: 69-76, 1988.

RÉSUMÉ: Nous présentons ici quelques considérations concernant la confrontation/rencontre entré la philosophie et la littérature. Dans la littérature brésilienne contemporaine, l'oeuvre de Clarice Lispector nous offre l'occasion d'analyser l'oeuvre d'art d'un point de vue interdisciplinaire.

UNITERMES: Philosophie; littérature; philosophie et littérature; examen interdisciplinaire; Clarice Lispector; littérature brésilienne.

\section{REFERÊNCIAS BIBLIOGRÁFICAS}

1. BORELLI, O. - Clarice Lispector. Esboço para um possivel retrato. Rio de Janeiro, Nova Fronteira, 1981.

2. BOSI, A. - História concisa da literatura brasileira. São Paulo, Cultrix, 1972.

3. FERNANDES, J. - O existencialismo na ficção brasileira. Goiânia, Ed. da Universidade Federal de Goiás, 1986.

4. FINAMOUR, J. - Clarice Lispector. Jornal de Letras, (133): 2, set. 1960.

5. FOUCAULT, M. - As palavras e as coisas; uma arqueologia das ciências humanas. Trad. Antonio Ramos Rosa. Lisboa, Portugalia Ed. 1968. (Coleção Problemas - 23).

6. GALVĀO NOGUEIRA, W. - Mitologia rosiana. São Paulo, Editora Ática, 1978.

7. GAOS, J. - Introducción a el ser y el tiempo de Martin Heidegger. México, Fondo de Cultura Económica, 1983.

8. GLOSSÁRIO de Derrida - trabalho realizado pelo Departamento de Letras da PUC/Rio com a supervisão de Silviano Santiano. Rio de Janeiro, F. Alves, 1976.

9. HEIDEGGER, M. - El ser y el tiempo. Trad. José Gaos. Tercera reimpresión. México, Fondo de Cultura Económica, 1983.

10. LIMA COSTA, L. - A literatura no Brasil. Organização de Afrânio Coutinho. Rio de Janeiro, Editorial Sul Americana, 1970. v. 5. 
11. LISPECTOR, C. - A descoberta do mundo (crónicas). Rio de Janeiro, Nova Fronteira, 1984.

12. LISPECTOR, C. -A paixão segundo G. H. 5ª ed. Rio de Janeiro, J. Olympio, 1977.

13. LISPECTOR, C. - Para não esquecer (crônicas). São Paulo, Ática, 1978.

14. LOUZADA FILHO, O. C. - A insustentável leveza do Ser. Kundera: o romance e o peso do conceito. O Estado de São Paulo, São Paulo, 1 dez. 1985. Suplemento Cultural, 5(285): 10.

15. MASSAUD, M. - A criação literária. São Paulo, Melhoramentos, 1967.

16. MERLEAU-PONTY, M. - Sens et non-sens. Paris, Nagel, 1948.

17. NIETZSCHE, F. - Le livre du philosophe. Trad., intr., et notes par Angèle K. Marietti. Paris, Aubier-Flammarion, 1969.

18. NUNES, B. - Leitura de Clarice Lispector. São Paulo, Editora Quiron, 1973.

19. NUNES, B. - O mundo imaginário de Clarice Lispector. In: O dorso do tigre. São Paulo, Perspectiva, 1986.

20. NUNES, B. - Literatura e filosofia: (Grande Sertão: veredas). In: LIMA, L. C. - Teoria da literatura em suas fontes. Rio de Janeiro, Francisco Alves, 1983. v. 1, p. 188-207.

21. SÁ, O. de - A escritura de Clarice Lispector. Petrópolis, Editora Vozes Ltda., Lorena/SP, Faculdades Integradas Tereza D'Ávila, 1979.

22. SÁ, O. de - Clarice Lispector: a travessia do oposto. São Paulo, PUC, 1983/84. (Tese - Doutoramento). 